
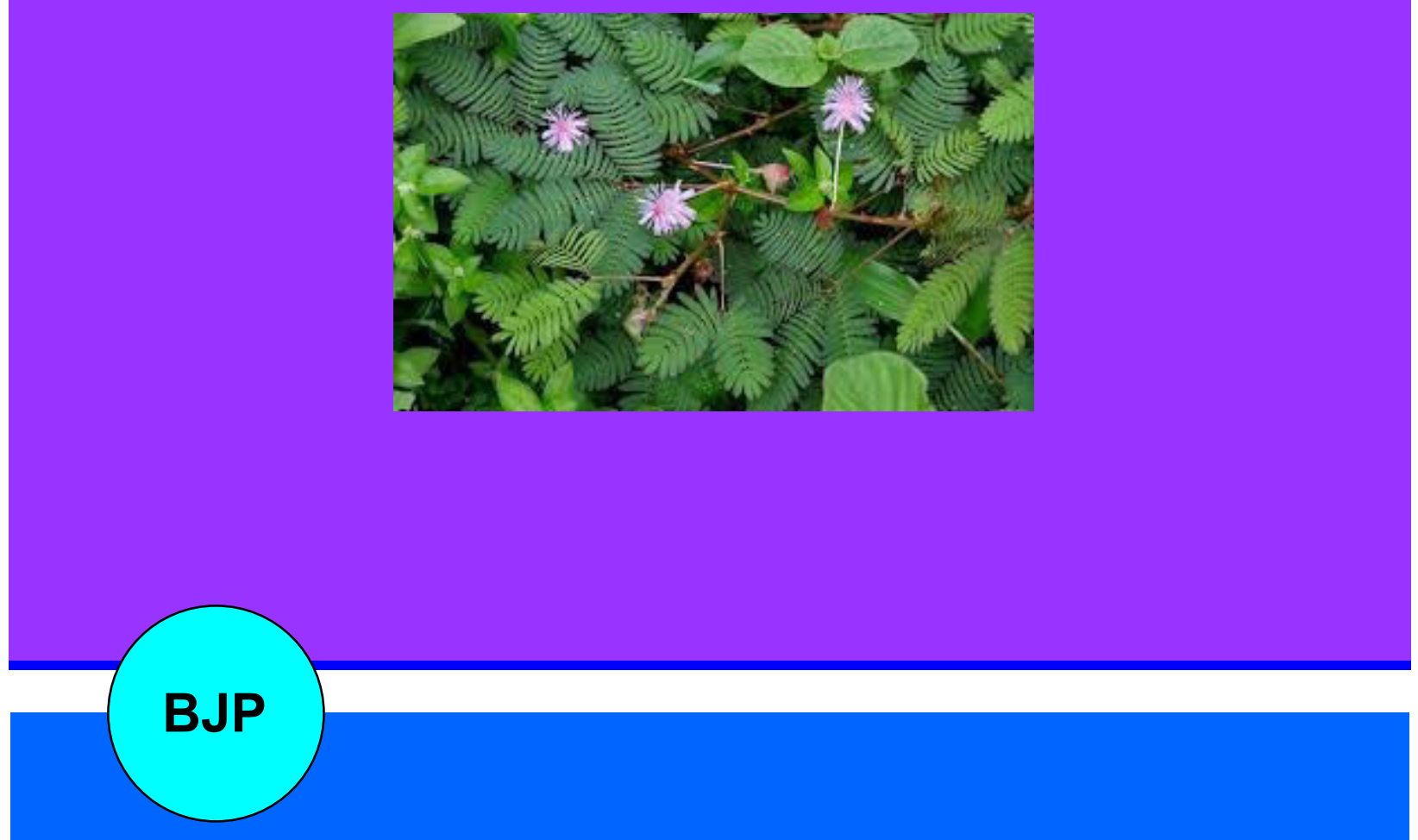

Bangladesh Journal of Pharmacology

Research Article

Antitoxin activity of Mimosa pudica

root extracts against Naja naja and

Bangarus caerulus venoms 


\title{
Antitoxin activity of Mimosa pudica root extracts against Naja naja and Bangarus caerulus venoms
}

\author{
Subramani Meenatchisundaram', Selvin Priyagrace', Ramasamy Vijayaraghavan', \\ Ambikapathi Velmurugan', Govindarajan Parameswari² and Antonysamy Michael²
}

${ }^{1}$ Department of Microbiology, Nehru Arts and Science College, Coimbatore, India; ${ }^{2}$ Department of Microbiology, PSG College of Arts and Science, Coimbatore, India.

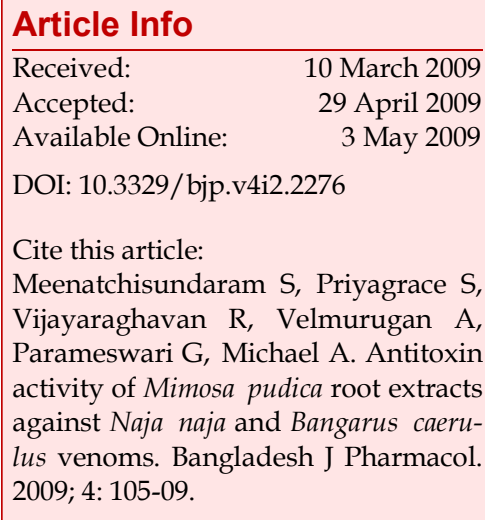

\section{Abstract}

Aqueous extract of dried roots of Mimosa pudica was tested for inhibitory activity on lethality, phospholipase activity, edema forming activity, fibrinolytic activity and hemorrhagic activity of Naja naja and Bangarus caerulus venoms. The aqueous extract displayed a significant inhibitory effect on the lethality, phospholipase activity, edema forming activity, fibrinolytic activity and hemorrhagic activity. About 0.14 and $0.16 \mathrm{mg}$ of $M$. pudica extracts were able to completely neutralize the lethal activity of $2 L_{50}$ of Naja naja and Bangarus caerulus venoms respectively. The present finding suggests that aqueous extract of $M$. pudica root possesses compounds, which inhibit the activity of Naja naja and Bangarus caerulus venoms.

\section{Introduction}

Snakebite is a major health hazard that leads to high mortality rate especially in India. The common poisonous snakes found in India are cobra (Naja naja), krait (Bangarus Caeruleus), Russell's viper (Daboia russelli) and saw scaled viper (Echis Carinatus) (Bawaskar, 2004). About 35,000 to 50,000 people die of snakebite every year in India. The venoms of cobra and krait of Elapidae family are neurotoxic in nature, considered to attack victim's central nervous system and usually results in heart failure. Their venom constitutes three types of proteins namely cardiotoxins, neurotoxins and phospholipase $\mathrm{A}_{2}$ which are responsible for various toxic activities in patients with snakebite. Antivenom immunotherapy is the only specific treatment against snake venom envenomation. There are various side effects of antivenom such as anaphylactic shock, pyrogen reaction and serum sickness. Most of these symptoms may be due to the action of high concentrations of non-immunoglobulin proteins present in commercially available hyper immune antivenom
(Devi et al., 2002). Over the years many attempts have been made for the development of snake venom antagonists especially from plants sources. Several medicinal plants, which appear in old drug recipes or which have been passed on by oral tradition, are believed to be snakebite antidotes. Many Indian medicinal plants are recommended for the treatment of snakebite (Alam et al., 2003). Some of these plant extracts has shown antivenom property on land snakes and their possible mechanism of action have been suggested. In almost any part of the world, where venomous snakes occur, numerous plant species are used as folk medicine to treat snakebite. The present investigation explored the cobra and krait venom neutralizing activity of Mimosa pudica plant extracts by in vivo and in vitro methods.

\section{Materials and Methods}

\section{Venom and experimental animals}

The free-dried snake venom powders of cobra and 
krait were obtained from Irula's Snake Catchers Industrial Co-operative Society Limited, Chennai and was stored at $4^{\circ} \mathrm{C}$. Male inbreed Swiss albino mice 18$20 \mathrm{~g}$ were used for efficacy studies.

\section{Medicinal plant and preparation of extract}

M. pudica plants were collected from Nehru Gardens of Nehru Arts and Science College. The extraction was carried out by the method of Uhegbu et al. (2005) using distilled water as the solvent. $20 \mathrm{~g}$ of powdered sample of the herb was extracted by soaking in $180 \mathrm{~mL}$ of distilled water in a beaker, stirred for about $6 \mathrm{~min}$ and left overnight. Thereafter, the solution was filtered using filter paper (Whatman No. A1) and the extracts were evaporated to dryness under reduced pressure below $40^{\circ} \mathrm{C}$. The plant extracts were expressed in terms of dry weight.

\section{Lethal toxicity}

The median lethal dose ( $\left.\mathrm{LD}_{50}\right)$ of cobra and krait venom was determined according to the method developed by Theakston and Reid, 1983. Various doses of venom in $0.2 \mathrm{~mL}$ of physiological saline was injected into the tail vein of mice (18-20 g), using groups of 3-5 mice at each venom dose. The $\mathrm{LD}_{50}$ was calculated with the confidence limit at $50 \%$ probability by the analysis of deaths occurring within 24 hours of venom injection. The anti-lethal potentials of M. pudica plant extracts were determined against $2 L^{2} D_{50}$ of cobra and krait venom. Various amount of plant extracts $(\mu \mathrm{L})$ were mixed with $2 \mathrm{LD}_{50}$ of venom sample and incubated at $37^{\circ} \mathrm{C}$ for $30 \mathrm{~min}$ and then injected intravenously into mice. 3-5 mice were used at each antivenom dose. Control mice received same amount of venom without antivenom (plant extracts). The median effective dose $\left(\mathrm{ED}_{50}\right)$ calculated from the number of deaths within 24 hours of injection of the venom/antivenom mixture. The $E_{50}$ was expressed as $\mu \mathrm{L}$ antivenom/mouse and calculated by probit analysis.

\section{Edema-forming activity}

The minimum edema-forming dose (MED) of cobra and krait venom was determined by the method of Lomonte et al. (1993) and Camey et al. (2002). The MED was defined as the least amount of venom which when injected subcutaneously into mice footpad results in 30\% edema with in 6 hours of venom injection. The thickness of each footpad was measured every $30 \mathrm{~min}$ after venom injection with a low-pressure spring caliper (Rojas et al., 2005). The ability of $M$. pudica extract in neutralizing the edema-forming activity were carried out by pre-incubating the constant amount of venom and various dilutions $M$. pudica plant extracts and incubated for $30 \mathrm{~min}$ at $37^{\circ} \mathrm{C}$. Then, groups of four mice (18-20 g) were injected subcutaneously in the right footpad with $50 \mathrm{~mL}$ of the mixtures, containing venom/plant extracts, whereas the left footpad received $50 \mathrm{~mL}$ of PBS alone. Control mice were injected with venom in the right footpad and $50 \mathrm{~mL}$ of PBS in the left footpad. 1 hour after injection edema was evaluated as described by Yamakawa et al., 1976. Edema was expressed as the percentage increase in thickness of the right footpad compared to the right footpad of the control mice.

\section{Hemorrhagic activity}

The minimum hemorrhagic dose (MHD) of cobra and krait venom was determined by the method described by Theakston and Reid, 1983. The minimum hemorrhagic dose was defined as the least amount of venom which when injected intradermally into mice results in a hemorrhagic lesion of $10 \mathrm{~mm}$ diameter in 24 hours. Neutralization of the hemorrhagic activity was estimated by mixing a fixed amount of venom with different amounts plant extracts. The plant extractvenom mixture was incubated at $37^{\circ} \mathrm{C}$ for 1 hour and $0.1 \mathrm{~mL}$ of the mixture was injected intradermally into mice. The hemorrhagic lesion was estimated after 24 hours.

\section{Phospholipase activity}

Phospholipase $\mathrm{A}_{2}$ activity was measured using an indirect hemolytic assay on agarose-erythrocyte-egg yolk gel plate by the methods described by Gutierrez et al., 1988. Increasing doses of cobra and krait venom $(\mu \mathrm{g})$ was added to $3 \mathrm{~mm}$ wells in agarose gels $(0.8 \%$ in PBS, pH 8.1) containing $1.2 \%$ sheep erythrocytes, $1.2 \%$ egg yolk as a source of lecithin and $10 \mathrm{mM} \mathrm{CaCl}_{2}$. Slides were incubated at $37^{\circ} \mathrm{C}$ overnight and the diameters of the hemolytic halos were measured. Control wells contained $15 \mu \mathrm{L}$ of saline. The minimum indirect hemolytic dose (MIHD) corresponds to a dosage of venom, which produced a hemolytic halo of $11 \mathrm{~mm}$ diameter. The efficacy of M. pudica extract in neutralizing the phospholipase activity was carried out by mixing constant amount of venom $(\mu \mathrm{g})$ with different amount of plant extract $(\mu \mathrm{L})$ and incubated for $30 \mathrm{~min}$ at $37^{\circ} \mathrm{C}$. Then, aliquots of $10 \mathrm{~mL}$ of the mixtures were added to wells in agarose-egg yolk-sheep erythrocyte gels. Control samples contain venom without plant extracts. Plates were incubated at $37^{\circ} \mathrm{C}$ for 20 hours. Neutralization expressed as the ratio $\mathrm{mg}$ antibodies/ mg venom able to reduce by $50 \%$ the diameter of the hemolytic halo when compared to the effect induced by venom alone.

\section{Procoagulant activity}

The procoagulant activity was done according to the method described by Theakston and Reid, 1983 modified by Laing et al., 1992. Various amounts of venom dissolved in $100 \mu \mathrm{L}$ PBS (pH 7.2) was added to human citrated plasma at $37^{\circ} \mathrm{C}$. Coagulation time was recorded and the minimum coagulant dose (MCD) was determined as the venom dose, which induced 
clotting of plasma within 60 sec. Plasma incubated with PBS alone served as control. In neutralization assays constant amount of venom was mixed with various dilutions of $M$. pudica extracts. The mixtures were incubated for $30 \mathrm{~min}$ at $37^{\circ} \mathrm{C}$. Then $0.1 \mathrm{~mL}$ of mixture was added to $0.3 \mathrm{~mL}$ of citrated plasma and the clotting times recorded. In control tubes plasma was incubated with either venom alone or plant extracts alone. Neutralization was expressed as effective dose (ED), defined as the ratio $\mathrm{mL}$ antivenom (plant extracts)/mg venom at which the clotting time increased three times when compared with clotting time of plasma incubated with two MCD of venom alone.

\section{Fibrinolytic activity}

A modified plaque assay was used (Rojas et al., 1987). The minimum fibrinolytic concentration was defined as the concentration of venom that induced a fibrinolytic halo of $10 \mathrm{~mm}$ diameter. Neutralization experiments were performed by incubating a constant amount of venom with varying amount of $M$. pudica plant extracts at $37^{\circ} \mathrm{C}$ for 1 hour. After incubation, the mixture was applied to the wells in the plaque. After 18 hours of incubation at $37^{\circ} \mathrm{C}$, fibrinolytic halos were measured.

\section{Statistical analysis}

Statistical evaluation was performed using XL stat
2007 and SPSS 10 Software. $P<0.005$ was considered statistically significant.

\section{Results}

The antivenom potential of M. pudica plant extract was tested against cobra and krait venom by in vivo and in vitro methods. The lethal toxicity $\left(\mathrm{LD}_{50}\right)$ of cobra and krait venom was assessed using $18 \mathrm{~g}$, Balb/c strain mice. About $10 \mu \mathrm{g}$ of cobra and $3 \mu \mathrm{g}$ of krait venom was found to be $\mathrm{LD}_{50}$ for $18 \mathrm{~g}$ of mice. The neutralization of lethality was done by mixing constant amount of venom $\left(2 L_{50}\right)$ with various dilutions of $M$. pudica plant extracts and incubated at $37^{\circ} \mathrm{C}$ for $30 \mathrm{~min}$ prior to injection. We found that $0.14 \mathrm{mg}$ and $0.16 \mathrm{mg}$ of M. pudica plant extracts were able to completely neutralize the lethal activity of $2 \mathrm{LD}_{50}$ of Naja naja and Bangarus caerulus venom respectively.

In edema forming activity, the mice immunized with cobra and krait venoms showed increase in footpad thickness. About $7 \mu \mathrm{g}$ of cobra and $7 \mu \mathrm{g}$ of krait venom induced edema formation within 3 hours which is considered as $100 \%$ activity. The edema was reduced up to $30 \%$ when $2.5 \mathrm{mg}$ of plant extract per mg venom was given. There was no further reduction in the percentage of edema even when there was an increase in antivenom dose (Figure 1).

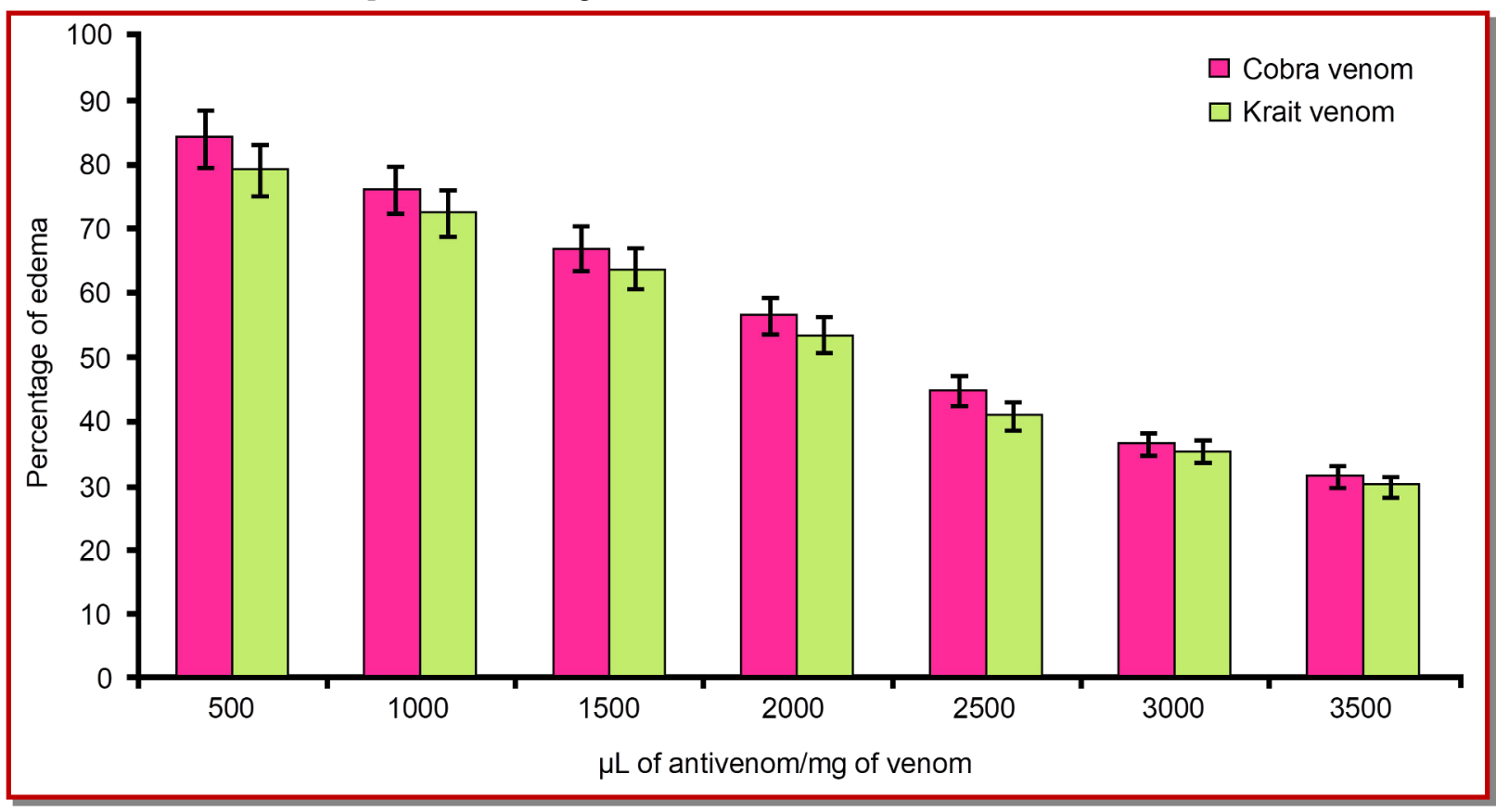

Figure 1: Neutralization of edema induced by Cobra and Krait venom by Mimosa pudica plant extracts in experiments with preincubation. Various mixtures of Cobra and Krait venom and Mimosa pudica plant extracts were incubated and tested in the footpad assay. Edema was assessed 1 hour after injection and expressed as percentage. Edema induced in control mice (venom alone) was considered as $100 \%$ activity. Mimosa pudica plant extracts inhibited the edema forming activity and edema was reduced up to $30 \% . \mathrm{P}<0.005$ at all antivenoms/venom ratios. 
In the case of hemorrhagic activity, cobra and krait venom did not produced any visible hemorrhagic spot. In phospholipase $\mathrm{A}_{2}$ activity, cobra and krait venom able to produce hemolytic haloes in agarose-sheep erythrocytes gels. About $15 \mu \mathrm{g}$ of cobra and $10 \mu \mathrm{g}$ of krait venom produced $11 \mathrm{~mm}$ diameter hemolytic halo, which is considered to be $1 \mathrm{U}(\mathrm{U} / 10 \mu \mathrm{g})$. This shows that cobra and krait venoms have the enzymes (phospholipase $\mathrm{A}_{2}$ ) that has the ability to lyse sheep RBC's. M. pudica extracts were capable of inhibiting phospholipase $\mathrm{A}_{2}$ dependant hemolysis of sheep RBC's induced by cobra and krait venom in a dosedependant manner. We found that that $0.14 \mathrm{mg}$ and $0.16 \mathrm{mg}$ of $M$. pudica plant extracts were able to completely inhibit phospholipase $\mathrm{A}_{2}$ dependent hemolysis of sheep RBC's induced by cobra and krait venom respectively.

The MCD was determined as the venom dose inducing clotting of plasma in $60 \mathrm{sec}$. About $60 \mu \mathrm{g}$ of cobra and krait venom clotted human citrated plasma within 60 sec. In the neutralization assay, the absence of clot formation shows the neutralizing ability of both plant extracts. We found that $1.4 \mathrm{mg}$ of M. pudica plant extracts were able completely to neutralize coagulant activity. High dose of venom caused rapid clotting that required very high dose of antivenom to neutralize. The fibrinolytic effect was effectively antagonized by the M. pudica plant extract. The $\mathrm{ED}_{50}$ of $M$. pudica were found to be 0.7 and $0.9 \mathrm{mg}$ for cobra and krait respectively.

\section{Discussion}

Snakebite is a major health hazard that leads to high mortality rate especially in India. Antisnake venom remains the specific antidote for snake venom poisoning. This antisnake venom are usually derived from horse sera. They contain horse immunoglobulins, which frequently caused complement mediated side effects, and other proteins that cause serum sickness and occasionally, anaphylactic shock. Although, use of plants against the effects of snakes bite has been long recognized, more scientific attention has been given since last 20 years (Fattepur and Gawade, 2007). Many Indian medicinal plants are recommended for the treatment of snakebites (Alam et al., 2003). In our present study we check the antivenom potential of $M$. pudica plant extracts against cobra and krait venom. Various pharmacological activities like lethality, edema forming activity, hemorrhagic activity, fibrinolytic activity, phospholipase $A_{2}$ activity, procoagulant activity caused by cobra and krait venom were carried out. Neutralization of these pharmacological effects was carried out using M. pudica plant extract. Neutralization studies can be performed by incubating of venom and plant extract prior to testing (preincubation method). The results showed that the $M$. pudica plant extract was capable of neutralizing the lethality induced by the venom. The cobra and krait venom showed the presence of phospholipase $A_{2}$ enzymes by producing hemolytic haloes in indirect hemolytic assays. M. pudica plant extract was capable of inhibiting phospholipase $\mathrm{A}_{2}$ dependent hemolysis of sheep RBCs in a dose dependent manner. Edemaforming activity was assessed for cobra and krait venom and M. pudica plant extract was found to be effective in neutralization of edema induced by venoms. There was a significant decrease in the edema (footpad thickness) when there was an increase in the antivenom (plant extract) dose. Procoagulant activity induced by cobra and krait venom was studied using human citrated plasma and M. pudica plant extract was found to be effective in the neutralization of procoagulant activity. M. pudica plant extract was effectively antagonised the fibrinolytic activity. The main conclusion of this study is that the present experimental results show that $M$. pudica plant extract was effective in neutralizing the main toxic effects of the cobra and krait venoms. The potency of the antivenom antibodies can still increase with the use of highly purified plant extracts.

\section{Financial Support}

Self-funded

\section{Ethical Issue}

Institutional Animal Ethics Committee clearance at Institute of vector control and Zoonooses, Hosur, was obtained to conduct the experiment.

\section{Conflict of Interest}

Authors declare no conflict of interest

\section{Acknowledgement}

The authors would like to thank the Head, Department of Botany, S. P. M. M. Baramati, Pune, MS, for the identification of the plant

\section{Reference}

Alam MI, Gomes A. Snake venom neutralization by Indian medicinal plants (Vitex negundo and Emblica officinalis) root extracts. J Ethnopharmacol. 2003; 86: 75-80. 
Bawaskar HS. Snake venoms and antivenoms: Critical supply issues. J Assoc Phys India. 2004; 52: 11-13.

Camey KU, Velarde DT, Sanchez EF. Pharmacological characterization and neutralization of the venom used in the production of Bothropic antivenom in Brazil. Toxicon 2002; 40: 501-09.

Devi CM, Bai MV, Lal AV, Umashankar PR, Krishnan LK. An improved method for isolation of anti-viper venom antibodies from chicken egg yolk. J Biochem Biophy Methods. 2002; 51: 129-38.

Fattepur SR, Gawade SP. Preliminary screening of herbal plant extracts for anti-venom activity against common sea snake (Enhydrina schistosa) poisoning. Phcog Mag. 2007; 3: 56-60.

Gutierrez JM, Avila C, Rojas E, Cerdas L. An alternative in vitro method for testing the potency of the polyvalent antivenom produced in Costa Rica. Toxicon 1988; 26: 411-13.

Laing GD, Theakston RDG, Leite RP, Dias Da Silva WD, Warrell DA. Comparison of the potency of three Brazilian Bothrops antivenoms using in vivo rodent and in vitro assays. Toxicon 1992; 30: 1219-25.

Lomonte B, Tarkowski A, Hanson HA. Host response to Bothrops asper snake venom: Analysis of edema formation, inflammatory cells, and cytokine release in mouse model.
Inflammation 1993; 17: 95-105.

Rojas G, Guturrez JM, Gene JM, Gomez M, Cerdas L. Neutralization de las actividades toxicas $Y$ enzimaticas de cuatro venenos de rerpipentes de Guatemala Y Honduras por el antivenenopolivalente producido en Costa Rica. Revista de Biol Trop. 1987; 35: 59-67.

Rojas E, Quesada L, Arce V, Lomonte B, Rojas G, Gutierrez JM. Neutralization of four Peruvian Bothrops sp. snake venoms by polyvalent antivenoms produced in Peru and Costa Rica: Preclinical assessment. Acta Tropica. 2005; 93: 85-95.

Theakston RDG, Reid HA. Development of simple standard assay procedures for the characterization of snake venoms. Bull WHO. 1983; 61: 949-56.

Uhegbu FO, Elekwa I, Ukoha C. Comparative efficacy of crude aqueous extract of Mangifera indica, Carica papaya and sulphadoxine pyrimethamine on the mice infested with malaria parasite in vivo. Global J Pure Appl Sci. 2005; 11: 399 -401 .

Yamakawa M, Nozaky M, Hokama Z. Fractionation of sakishimahabu (Trimeresurus elegans) venom and lethal, hemorrhagic and edema-forming activities of the fractions. In: Toxins: Animal, plant and microbial. Ohsaka A, Hayashi K, Sawai Y (eds). New York, Plenum Press, 1976, pp 97-109. 